\title{
APLICATIVO PARA DISPOSITIVOS MÓVEIS VOLTADO PARA SIMULAÇÃO DE CRÉDITO RURAL
}

\author{
Vinicius Steindorf Rommel \\ Bacharel em Sistemas de Informação \\ Universidade do Oeste de Santa Catarina - UNOESC \\ Chapecó, SC \\ vinicius.rommel@unoesc.edu.br
}

\author{
Wagner Titon \\ Mestre em Computação Aplicada \\ Universidade do Vale do Itajaí - Univali \\ Chapecó, SC \\ wagner.titon@unoesc.edu.br
}

\begin{abstract}
O Governo Federal através do crédito rural oferece a todos os agricultores a possibilidade de investimentos em sua propriedade, custeio para lavouras e também crédito para comercialização. As taxas de juros das linhas de crédito que apoiam o crédito rural são inferiores as demais disponíveis no âmbito financeiro, assim como carências e prazos de pagamento maiores, facilitando desta forma a obtenção e quitação de financiamentos. Com o intuito de auxiliar a todos os agricultores, unindo tecnologia e crédito rural, surgiu o aplicativo "Sirural", que se trata de um aplicativo para simulação de crédito rural. Para efetuar uma simulação, este aplicativo coleta informações disponibilizadas pelo usuário e de acordo com alguns parâmetros especificados em seu desenvolvimento, faz a entrega da linha de crédito que melhor se adequa as necessidades do usuário. Com o propósito de validar o aplicativo desenvolvidos, definiu-se dois grupos de testes para analisar se o aplicativo atende as necessidades dos agricultores rurais no âmbito de financiamentos rurais. $O$ primeiro grupo contou com quatorze agricultores rurais, e do segundo grupo participaram cinco profissionais que atuam com crédito rural diariamente. A fim de buscar resultados, foi empregado um questionário que cada usuário após uso do aplicativo tinha a necessidade de responder. Os resultados finais do questionário permitiram observar que a média final de concordância das questões resultou em $67 \%$, o ponto de atenção se dá ao observar que o aplicativo conseguiu simular o financiamento de acordo com a necessidade do usuário $95 \%$ das vezes.
\end{abstract}

Palavras-chave: Crédito Rural; Ionic; Aplicativo; Android; Simulação Rural.

\section{INTRODUÇÃO}

Em dados preliminares divulgados pelo IBGE (2018), referente ao Censo Agropecuário de 2017, dados mostram que os números de estabelecimentos de agricultura familiar aumentaram, são aproximadamente $\quad 5.072 .152$ estabelecimentos e 15.036.978 pessoas estão ocupadas e trabalhando nestes. No contexto agrícola, a agricultura familiar que é composta por pequenos e médios produtores rurais, e são uma das fontes que mais colocam alimentos nas mesas dos brasileiros. De acordo com Figueiredo (2017), existem aproximadamente 11,5 milhões agricultores familiares no Brasil, cita também que alimentos como mandioca, feijão, café, arroz, e trigo, além da produção de leite e criação de suínos e aves, provem essencialmente da agricultura familiar.

A partir do potencial e dos números positivos providos da agricultura familiar, diversos segmentos da economia começaram a voltar seu foco também a este público, que mesmo sem tantos recursos disponíveis, utilizam empréstimos e financiamentos para investir em suas propriedades, que também através da tecnologia, adaptam as propriedades rurais, sempre em busca de melhor produtividade e consequente rentabilidade.

O principal objetivo deste trabalho foi simplificar para todos os agricultores no que se refere a simulação de crédito rural através de um dispositivo móvel, que nos dias de hoje está amplamente difundido entre as pessoas. Com o uso deste aplicativo o usuário certamente evitará movimentações desnecessárias até um agente financeiro que tenha produtos voltados ao crédito rural, inicialmente para ter conhecimento dos valores a serem pagos, sendo que há possibilidade de o agente financeiro em questão não ter disponível a linha de crédito que melhor se encaixa na necessidade do produtor rural.

\section{REVISÃO BIBLIOGRÁFICA}

Visando aprofundar o conhecimento sobre o tema deste trabalho, em seguida apresentam-se os seguintes tópicos: Crédito Rural, Tecnologia e Agricultura e Tecnologias de Desenvolvimento.

\section{A. CRÉDITO RURAL}

O crédito rural foi inserido em nossa Constituição no dia 05 de novembro de 1965 , pela Lei 4.829 e em 10 de maio de 1966 foi regulamentado, pelo Decreto 28.380 Com este Decreto, disciplinou-se os recursos financeiros ao setor agrícola. O Banco Central do Brasil (2018), conceitua o crédito rural como suprimento de recursos financeiros, por instituições vinculados ao Sistema Nacional de Crédito Rural (SNCR), para aplicação exclusiva e condições que são estabelecidas no Manual do Crédito Rural (MCR).

No que se refere como início do crédito rural, o ponto marcante é a instituição do Sistema Nacional de Crédito Rural (SNCR), de acordo com Mata (1982), este Sistema foi criado em 1965 com a finalidade de regulamentar o fornecimento de crédito às atividades agropecuárias, em condições especiais. Tal afirmação tende a imaginarmos que a instituição deste Sistema agradou e beneficiou a todos, entretendo Fossá (et al., 2018 apud GRAZIANO NETO, 1982), cita que mesmo com a implementação desse sistema a concessão de crédito rural não ocorreu de forma igualitária, grande parte do volume do crédito rural foi direcionada para os grandes produtores, deixando os pequenos agricultores com recursos para financiamento limitados. Na época do lançamento do SNCR, as taxas aplicadas eram aproximadamente $25 \%$ menor que as 
demais taxas do mercado, e os juros até meados do ano de 1980 eram negativos, por não acompanharem o aumento da inflação.

A partir de 1980 o quadro econômico recessivo se instalou no final dos anos 1970, o endividamento externo, a falta de capital estrangeiro e altos níveis de inflação interferiram diretamente no montante de recursos que seriam destinados ao setor agrícola. Como os recursos para a agricultura diminuíram, os demais setores sofreram com o mesmo problema, diminui-se então o nível de investimento, o que para Fossá (et al., 2018 apud Sayad), comprometeu a capacidade produtiva em médio prazo. $\mathrm{Na}$ mesma linha de pensamento, Ramos e Junior (2010) afirmam que as graves dificuldades impostas no cenário macroeconômico daquela época, caracterizadas pela intensificação do processo de inflação e pela crise no estado, acabaram impedindo que o Governo continuasse como o principal supridor de recursos para o crédito rural, e a partir disso, iniciou-se então um realinhamento no crédito rural, reduzindo por exemplo a participação direta do governo na concessão de financiamentos.

O cenário começou a mudar com a instituição do Programa Nacional do Fortalecimento da Agricultura Familiar - Pronaf, no ano de 1996, com a finalidade de igualar o crédito oficial, que favorecia essencialmente grandes produtores rurais. Desde aquela época, até os anos atuais, o Pronaf é que apresenta os menores encargos financeiros entre todos disponibilizados pelo SNCR. Com a criação do Pronaf, os anos de 2000 prometia ser um dos períodos de maior evolução do Crédito Rural, e a expectativa se concretizou, no período de 1997 a 1999, o volume de crédito rural cresceu apenas 3,6\%, já entre os anos 2000 e 2005, atingiu 70,8\% de crescimento, passando a ter ao todo $\mathrm{R} \$ 50,8$ bilhões de crédito circulando. A evolução na outra metade dos anos 2000 foi ainda maior, houve crescimento de $148,0 \%$, totalizando $\mathrm{R} \$ 75,2$ bilhões em 2009. A expansão entre os anos 2000 e 2009 foi de $152,8 \%$ (RAMOS; MARTHA JUNIOR, 2010).

\section{B. TECNOLOGIA E AGRICULTURA}

Com a criação da Lei 4.829, e demais ações que vieram a ser tomadas nos anos subsequentes, o crédito rural avançou muito, até que, em dias atuais, não se fala em economia do país, sem falar da contribuição que a agricultura trás. $\mathrm{O}$ avanço das tecnologias no ambiente agrícola, também proporcionou grandes avanços na produção, auxiliando os agricultores de forma geral (FIGUEIREDO, 2017). A tecnologia está beneficiando a sociedade a todo momento, seja ela com lançamentos de novos produtos, aperfeiçoamentos de ferramentas, ou até mesmo, auxiliando as pessoas em tarefas simples que cotidianamente necessitam realizar.

Uma pesquisa realizada pelo Ibope em 2013 constatou que o brasileiro passa, em média 84 minutos por dia usando um smartphone. Com esses dados, é possível identificar que os smartphones estão cada vez mais presentes nas vidas das pessoas, e, se bem utilizados, podem se tornar uma ferramenta poderosa em vários aspectos, principalmente no acesso à informação. $\mathrm{Na}$ agricultura por exemplo, conforme dados levantados pelo Sebrae Santa Catarina (2017), "No Estado de Santa Catarina o percentual de produtores que usam aparelhos celulares é de 92,6\%".

\section{TECNOLOGIAS DE DESENVOLVIMENTO}

Para o desenvolvimento deste aplicativo toda a programação foi realizada buscando a utilização do aplicativo em plataforma Android, pois, conforme cita Mendonça (et al., 2011), [...] o desenvolvimento Android é multiplataforma podendo ser desenvolvido em qualquer dos principais sistemas operacionais: Windows (XP ou superior), Mac OS X (10.5.8 ou superior) e sistemas Linux. Conforme dados de Ciriaco (2017), em maio de 2017 o Android possuía 85\% do mercado de dispositivos mobile do mundo, enquanto o iOS possuía $14.7 \%$. É possível perceber que o Sistema Operacional Android é mais usado e difundido entre os dispositivos móveis, desta forma, ao realizar o desenvolvimento do aplicativo para esta plataforma, alcançaremos um número maior de pessoas, assim como, não foi necessário investir na aquisição de máquinas exclusivas para desenvolvimento (No caso do iOS).

A forma de desenvolvimento do aplicativo utilizada foi a híbrida, esse tipo de aplicação de acordo com Prezotto e Boniati (2016), possuem finalidade de funcionar em qualquer que seja o dispositivo, independentemente da plataforma, o mesmo código-fonte será utilizado. Aplicativos desenvolvidos de forma híbrida podem usar conexão com a internet, ou não, dependendo de sua finalidade. Aplicações híbridas, assim como as nativas, podem ser disponibilizadas nas lojas de aplicativos, pois ficam instaladas no aparelho. A grande vantagem de utilizar o desenvolvimento híbrido, é a redução de tempo para desenvolvimento do aplicativo, além de ter uma maior flexibilidade, pois é multiplataforma. Porém, também há desvantagens, se comparado ao aplicativo nativo, ele possui um desempenho inferior, porém, é apto a ser utilizado cotidianamente.

No que se refere a desenvolvimento da aplicação, o software utilizado foi o Ionic, que nada mais é que framework para desenvolvimento de aplicativos móveis multiplataforma, baseado em Cordova, e além disso é open source. Para que isso funcione bem, essa ferramenta possibilita a implementação de tecnologias comumente empregadas na construção do Front-End de soluções web: HTML, CSS e JavaScript. O Ionic traz consigo também outra linguagem e framework, a fim de facilitar seu uso e implementação, o framework em questão é o Angular e linguagem é o TypeScript (DEVMEDIA, 2018). Para Grillo (2015), “a grande vantagem do Ionic é que seu desenvolvimento foi pensado em utilizar os recursos mais novos do CSS, HTML e JavaScript com o objetivo de prover para o desenvolvedor uma gama de componentes pré-prontos de alta qualidade e desempenho".

\section{PROCEDIMENTOS METODOLÓGICOS}

A aplicação desenvolvida através deste estudo, está apta a ser utilizada por todas as regiões do Brasil, uma vez que as formas de apoio ao crédito rural e o plano safra do ano em exercício são as mesmas para todo o país. Serão utilizados apenas instituições financeiras que operam as linhas de crédito rural, por órgãos vinculados e por órgãos articulados, todos devem estar ligados diretamente com o Sistema Nacional de Crédito Rural (SNCR). É destacável o fato da aplicação ser direcionada exclusivamente aos pequenos e médios produtores rurais, cuja classificação é 
dada pela Receita Bruta Agropecuária Anual (RBA) auferida.

O trabalho desenvolvido foi uma pesquisa aplicada, no qual visa gerar conhecimento para a aplicação prática buscando sempre resolver problemas específicos, esse tipo de pesquisa envolve verdades e interesses locais (GERHARDT; SILVEIRA 2009). Da mesma forma, Vilaça (2010) descreve que na maioria dos casos, as pesquisas aplicadas exigem e partem de estudos teóricos. Cita também, que pesquisas aplicadas tem como principal objetivo resolver problemas ou necessidades da sociedade.

Para abordar o assunto, estre trabalho utilizou pesquisa qualitativa, que neste estudo os temas abordados foram pesquisar e analisar o crédito rural e tecnologias híbridas. Para Gerhardt e Silveira (2009), a pesquisa qualitativa preocupa-se, com aspectos da realidade que não podem ser quantificados, centrando-se na compreensão e explicação da dinâmica das relações sociais.

Para elaborar o trabalho os procedimentos técnicos utilizados foram pesquisa bibliográfica e documental.

A pesquisa bibliográfica é desenvolvida a partir de materiais já elaborados, principalmente livros e artigos científicos. A principal vantagem de utilizar a pesquisa bibliográfica está na grande possibilidade de coberturas que o investigador pode utilizar (GIL, 2008). Já a pesquisa documental, segundo Marconi e Lakatos (2003), possui características únicas, para os autores, a fonte de pesquisa de dados está restrita a documentos, escritos ou não, o que se denomina fonte primária.

Com o intuito de melhor analisar os resultados do aplicativo desenvolvido, testes foram efetuados com dois grupos de usuários, quatorze usuários testes que trabalham com a agricultura diariamente, e cinco pessoas que trabalham em Cooperativas de Crédito Rural, e que possuem conhecimento de linhas de crédito e suas particularidades. Todos os usuários que efetuaram os testes junto ao aplicativo possuem área de terra localizada na cidade de Paial-SC, alguns destes moram no município, outros moram na cidade de Chapecó-SC, mas mantem lavoura e criação de gados de corte no município supracitado.

Para efetuar a coleta e análise dos dados optou-se pela ferramenta questionário. A partir das respostas deste questionário se todos os objetivos e requisitos elencados foram atendidos parcialmente, totalmente ou se não foram atendidos. A avaliação se deu quanto à concordância ou discordância das questões avaliadas, através da obtenção do Ranking Médio da pontuação atribuída às respostas, relacionando à frequência das respostas dos usuários que responderam o questionário ou que fizeram tal atribuição, onde os valores menores que 3 são considerados como discordantes e, maiores que 3 , como concordantes, considerando uma escala de 5 pontos. $\mathrm{O}$ valor exatamente 3 seria considerado "indiferente" ou "sem opinião", sendo o "ponto neutro", equivalente aos casos em que os respondentes deixaram em branco. Para que todos os usuários pudessem entender a forma de pontuação, elas foram definidas como: Concordo, concordo parcialmente, não concordo nem discordo, discordo parcialmente e discordo.

O seguinte cálculo é efetuado para descobrirmos o ranking médio:

Média Ponderada $=(3 \times 2)+(2 \times 3)+(1 \times 4)=16$
Ranking Médio $=16 /(3+2+1)=2,7$

Para ser considerado apto a ser distribuído a todos usuários, o Ranking Médio estabelecido deveria ser superior a 2,8 pontos.

\section{ANÁLISE DOS DADOS}

A construção deste trabalho se deu essencialmente em sites governamentais, cujo o crédito rural é o principal foco, destaca-se essencialmente o Banco Central do Brasil, que foi a principal fonte de pesquisa, em seguida, destacase o Ministério de Desenvolvimento Agrário, Ministério da Agricultura, Pecuária e Abastecimento, leis impostas em território nacional, livros e artigos científicos. Se tratando de as fontes de pesquisa serem essencialmente retiradas de sites disponibilizados na internet, observa-se que se tratam de sites confiáveis e que são geridos pelo governo federal, tornando a pesquisa confiável e segura.

Quanto ao desenvolvimento da aplicação, para gerenciar as linhas de crédito foi criado uma aplicação web cujo somente o administrador possui acesso. $\mathrm{O}$ acesso é restrito uma vez que as linhas serão geridas por ele. A Ilustração 1 representa o cadastro de linhas de crédito na aplicação web.

Conforme já mencionado, foi desenvolvido um aplicativo para sistema operacional android, no qual todos os usuários que desejarem podem ter acesso, basta ir até a Play Store e fazer o download do aplicativo denominado "Sirural". A Ilustração 2 apresenta as telas do aplicativo desenvolvido.

Ilustração 1. Tela cadastro de linhas de crédito.

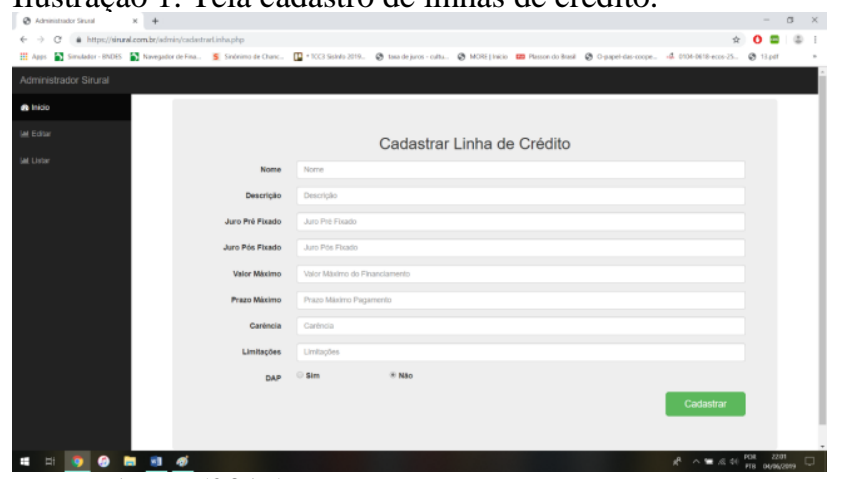

Fonte: Autor (2019).

Ilustração 2. Telas aplicativo.

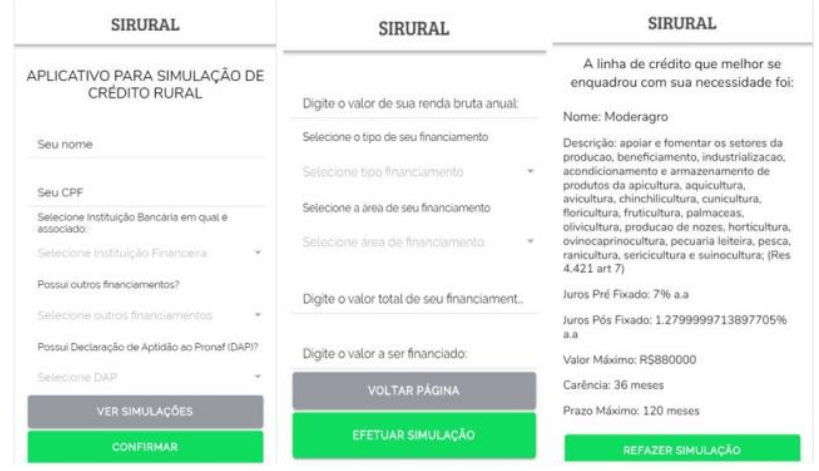

Fonte: Autor (2019).

Para realizar a comunicação entre o ambiente web, banco de dados e aplicativo, foi criado um web service na linguagem PHP. Basicamente o web service faz a requisição de três campos, os valores destes campos são 
recebidos do aplicativo. Em posse destas informações, são definidos alguns critérios através de condições e então o mesmo retornará ao aplicativo a melhor linha de crédito de acordo com sua necessidade.

Os testes com os dois grupos ocorreram durante uma semana, sendo que foram visitadas no total cinco famílias, no qual totalizou quatorze pessoas, e para validar a aplicação com análise mais crítica, foram efetuados testes com pessoas que diariamente trabalham com crédito rural e/ou agricultores, destes, apenas um trabalha com atendimento ao público. Cada usuário após utilizar o aplicativo obrigatoriamente teve de responder um questionário, cujo totalizadores estão dispostos na Tabela 1 a seguir.

Tabela 1. Resultado questionário.

\begin{tabular}{|c|c|c|c|c|c|}
\hline Questão & 1 & 2 & 3 & 4 & 5 \\
\hline $\begin{array}{l}\text { 1. O aplicativo } \\
\text { atendeu suas } \\
\text { expectativas? }\end{array}$ & $0 \%$ & $0 \%$ & $5 \%$ & $26 \%$ & $69 \%$ \\
\hline $\begin{array}{l}\text { 2. Recomendaria a } \\
\text { conhecidos ou } \\
\text { utilizaria o } \\
\text { aplicativo para } \\
\text { outras simulações? }\end{array}$ & $0 \%$ & $5 \%$ & $10 \%$ & $15 \%$ & $70 \%$ \\
\hline $\begin{array}{l}\text { 3. A disposição dos } \\
\text { elementos no } \\
\text { aplicativo foram } \\
\text { bem definidas? }\end{array}$ & $0 \%$ & $0 \%$ & $5 \%$ & $26 \%$ & $69 \%$ \\
\hline $\begin{array}{l}\text { 4. A simulação foi } \\
\text { fácil de ser } \\
\text { realizada? }\end{array}$ & $0 \%$ & $0 \%$ & $5 \%$ & $11 \%$ & $84 \%$ \\
\hline $\begin{array}{l}\text { 5. As mensagens } \\
\text { emitidas pelo } \\
\text { aplicativo são de } \\
\text { fácil entendimento? }\end{array}$ & $0 \%$ & $0 \%$ & $11 \%$ & $10 \%$ & $79 \%$ \\
\hline $\begin{array}{l}\text { 6. O aplicativo } \\
\text { conseguiu simular o } \\
\text { financiamento } \\
\text { conforme sua } \\
\text { necessidade? }\end{array}$ & $0 \%$ & $0 \%$ & $0 \%$ & $5 \%$ & $95 \%$ \\
\hline $\begin{array}{l}\text { 7. Utilizaria o } \\
\text { aplicativo ao invés } \\
\text { de ir até uma } \\
\text { instituição } \\
\text { financeira? }\end{array}$ & $11 \%$ & $10 \%$ & $26 \%$ & $16 \%$ & $37 \%$ \\
\hline $\begin{array}{l}\text { 8. A agilidade e } \\
\text { simplicidade na } \\
\text { simulação do crédito } \\
\text { foi perceptível? }\end{array}$ & $0 \%$ & $0 \%$ & $5 \%$ & $21 \%$ & $74 \%$ \\
\hline $\begin{array}{l}\text { 9. Você se sente } \\
\text { seguro ao ponto de } \\
\text { ir até uma } \\
\text { instituição } \\
\text { financeira e solicitar } \\
\text { a linha de crédito } \\
\text { indicada pelo } \\
\text { aplicativo? }\end{array}$ & $53 \%$ & $21 \%$ & $11 \%$ & $5 \%$ & $10 \%$ \\
\hline
\end{tabular}

Fonte: Autor (2019).
A seguir são apresentados os resultados das perguntas que mais chamaram atenção em seus totalizadores:

Referente a pergunta 4: A simulação foi fácil de ser realizada? A grande maioria das pessoas concordou com o fato. É possível notar que quase a totalidades dos usuários que testeram o aplicativo tiveram facilidade em efetuar a simulação. Com base nos relatos recebidos, o destaque se dá pelo fato das perguntas serem objetivas, além de necessitar pouca interação com o teclado do smartphone Outro destaque recebido é referente a disposição dos componentes na interface, além dos botões serem grandes e de fácil clique. Ainda referente ao resultado da pergunta 4, é importante destacar que o próprio framework ionic entrega a disposição dos componentes de forma agradável ao usuário, além de também possibilitar ajustes caso seja necessário. Com estes recursos pré prontos, a entrega de uma aplicação intuitiva aumenta consideravelmente.

Referente a pergunta 9: Você se sente seguro ao ponto de ir até uma instituição financeira e solicitar a linha de crédito indicada pelo aplicativo? A grande maioria dos usuários se necessitassem de um financiamento não iriam citar a sua institução financeira que já havia simulado o financiamento anteriormente. Quando argumentados de o porque confiar tanto sendo que o aplicativo entrega a mesma resposta, a razão foi que pela grande confiança que possuem nas pessoas que trabalham nas insituições, não haveria o porque de duvidar deles, porém, entenderam que o aplicativo também pode suprir sua necessidade em momentos semelhantes.

O resultado obtido é totalmente compreensível se analisarmos o fato de que, mesmo em dias atuais, os públicos das áreas rurais prezam muito por conversas e principalmente na confiança com o próximo, tanto com pessoas, como para com bancos ou outras organizações no qual fazem parte ou participam regularmente. É necessário tempo para que a visão das pessoas com uma tecnologia como essa se altere, adicionar em seu meio uma tecnologia que até o momento era feito em conversa com a instituição financeira é mudar de forma brusca o que de certa forma vem dando certo.

Referente a pergunta 6: O aplicativo conseguiu simular o financiamento conforme sua necessidade? Observou-se que quase a totalidade do público que utilizou o aplicativo conseguiu simular seu financiamento. Um resultado expresivo como este se dá essecialmente ao fato do aplicativo contar com várias possibilidade de simulação de financiamento, além é claro, da região pesquisada possuir algumas necessidades semelhantes, entre elas, podem ser citadas: Investimentos em galpões, cultivo de algumas culturas: Milho e soja, além é claro, de investimento para aquisição de bovinos leiteiros.

Para a elaboração do ranking médio, foram inicialmente definidas que as médias deveriam ser superiores a 2,8 pontos para considerá-lo útil a todas as pessoas, a

Ilustração 3 apresenta o ranking médio total de todas as questões.

Observa-se que somente a questão 9 impossibilitaria o uso da aplicação, porém, como não se trata de funcionalidade e sim de preferência dos usuários, o aplicativo pode ser considerado pronto a ser usado por qualquer usuário que sentir a necessidade de efetuar uma simulação rápida, simples e eficaz. 
Ilustração 3. Ranking médio.

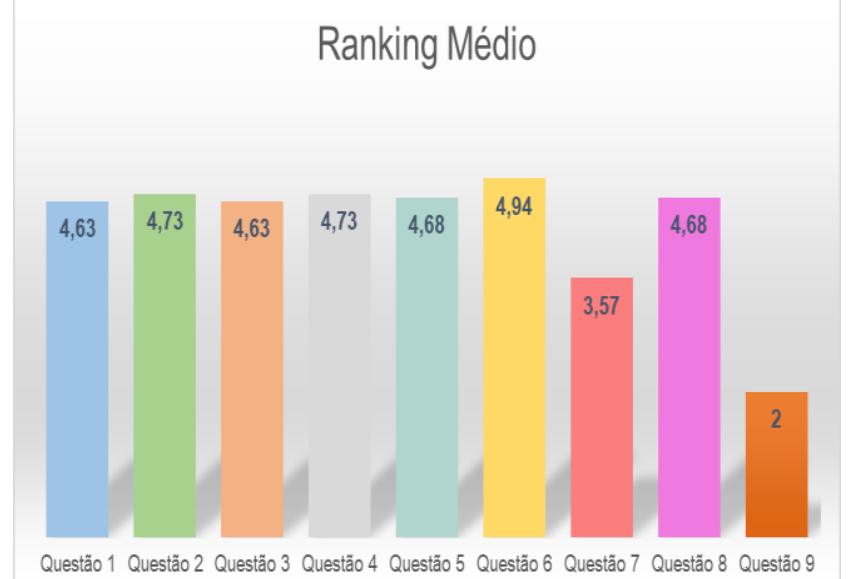

Fonte: Autor (2019).

\section{CONCLUSÃO}

O tema de estudo deste trabalho teve como objetivo geral entregar aos usuários um aplicativo mobile capaz de, através de parâmetros solicitados pelo aplicativo, indicar ao usuário a melhor linha de crédito disponível para sua necessidade, a fim de facilitar, especialmente, os pequenos e médios agricultores rurais quando o contexto se refere a financiamentos rurais.

Para se alcançar os objetivos, realizou-se inicialmente uma análise de mercado, avaliando a existência ou não de um aplicativo que atendesse a esta necessidade dos agricultores rurais. Após isso, aprofundou-se o estudo sobre a área de estudo escolhida, que neste caso foram agricultura e crédito rural. A tecnologia de desenvolvimento também foi tema de pesquisa e análise, nesta área investigou-se a plataforma e forma de desenvolvimento do aplicativo e então optou-se pelo desenvolvimento híbrido com a tecnologia Android.

Após superadas as fases citadas, iniciou-se o desenvolvimento do aplicativo e também de uma página para administração das linhas de crédito. Após a conclusão do desenvolvimento, iniciaram-se as intervenções com alguns agricultores rurais e profissionais que trabalham com crédito rural diariamente. Durante as intervenções foi necessário aplicar o método de avaliação desenvolvido, permitindo a mensuração do nível de satisfação do usuário durante o uso de aplicativo. Através do contato com profissionais que possuem conhecimento aprofundado na área, foram validadas as regras das indicações de financiamento de acordo com a necessidade dos usuários.

Através dos métodos de avaliação aplicados com os usuários teste do aplicativo, foram identificados alguns pontos de melhoria no que se refere ao layout da aplicação, algumas cores foram redefinidas, assim como o tamanho e disposição dos componentes na tela. No que se refere a entrega da simulação de acordo com a resposta dos parâmetros no aplicativo observou-se satisfação por parte do usuário, principalmente ao fato de estar disposto a ele todas as informações disponíveis em relação a linha de crédito indicada.

Com base nos resultados apresentados, é possível responder à pergunta de pesquisa inicialmente levantada: "O aplicativo permite simular as melhores linhas de crédito rural com base nos dados pré-definidos pelo usuário?". A resposta é afirmativa, uma vez que o aplicativo entregou ao usuário a linha de crédito que melhor se adequou com sua necessidade, a comprovação se dá se observarmos o ranking médio da questão 6 , o resultado obtido foi 4,94 pontos, o que representa a melhor pontuação entre todas as questões.

\section{REFERÊNCIAS}

[1] Banco Central do Brasil. Definições e conceitos sobre crédito rural. Disponível em: <http://www.bcb.gov.br/conteudo/mdcr/Documents/definicoesCred itoRural.pdf>. Acesso em: 17 maio 2018.

[2] DEVMEDIA. IONIC. Disponível

<https://www.devmedia.com.br/guia/ionic/38372>. Acesso em: 20 jun. 2018.

[3] FIGUEIREDO, Paulo. Agricultura familiar, um estímulo à economia brasileira. 2017. Disponível em: <https://www.campograndenews.com.br/artigos/agriculturafamiliar-um-estimulo-a-economia-brasileira>. Acesso em: 22 abr. 2018.

[4] FOSSÁ, Juliano Luiz; COMERLATTO, Dunia; CHEMIN, Patrícia. Crédito Rural no Brasil: das Concessões à Institucionalização de Políticas. Disponível em: < https://www2.faccat.br/portal/sites/default/files/fossa_comerlatto_c hemin.pdf>. Acesso em: 18 mai. 2018.

[5] GERHARDT, Tatiana Engel, SILVEIRA, Denise Tolfo. Métodos de pesquisa. Porto Alegre: Editora da UFRGS, 2009. Disponível em:

<http://www.ufrgs.br/cursopgdr/downloadsSerie/derad005.pdf>. Acesso em: 10 out. 2018.

[6] GIL, Antonio Carlos. Métodos e Técnicas de Pesquisa Social. São Paulo: Editora Atlas S.A, 2008.

[7] GRILLO, Rafael. Introdução ao Ionic Framework. 2015 Disponível em: <https://tableless.com.br/introducao-ao-ionicframework/>. Acesso em: 20 jun. 2018.

[8] IBGE. Censo Agro 2017: Resultado Preliminares. Disponível em: <https://censos.ibge.gov.br/agro/2017>. Acesso em: 12 ago. 2018.

[9] MARCONI, Marina de Andrade; LAKATOS, Eva Maria. Fundamentos de Metodologia Cientifica. São Paulo: Editora Atlas S.A, 2003.

[10] MATA, Milton da. Crédito Rural: Caracterização do sistema e estimativas dos subsídios implícitos. Revista Brasileira de Economia, Rio de Janeiro, v. 3, n. 36, p.215-245, jul. 1982.

[11] MENDONÇA, Vinicius Rafael Lobo de. BITTAR, Thiago Jabur., DIAS, Márcio de Souza. Um Estudo dos Sistemas Operacionais Android e IOS para o Desenvolvimento de Aplicativos. Góias: Enacomp, 2011. Anual. Disponível em: <http://www.enacomp.com.br/2011/anais/trabalhos-

aprovados/pdf/enacomp2011_submission_54.pdf >. Acesso em: 20 jun. 2018 .

[12] PREZOTTO, Ezequiel Douglas; BONIATI, Bruno Batista. Estudo de Frameworks Multiplataforma Para Desenvolvimento de Aplicações Mobile Híbridas. 2016. 8 f. TCC (Graduação) - Curso de Sistemas de Informação, Universidade Federal de Santa Maria, Santa Maria, 2016. Disponível

<http://www.eati.info/eati/2014/assets/anais/artigo8.pdf>. Acesso em: 20 jun. 2018 .

[13] RAMOS, Simone Yuri; MARTHA JUNIOR, Geraldo Bueno. Evolução da Política de Crédito Rural Brasileira. Planaltina: EMBRAPA Cerrados, 2010. (Documentos 292). Disponível em: <http://bbeletronica.cpac.embrapa.br/2010/doc/doc_292.pdf>. Acesso em: 18 mai. 2018.

[14] Sebrae Santa Catarina. Produtor rural catarinense é destaque em inovação no campo. 2017. Disponível em: <http://www.sebrae.com.br/sites/PortalSebrae/ufs/sc/noticias/produ tor-rural-catarinense-e-destaque-em-inovacao-no- 
campo,1de2ec958277d510VgnVCM1000004c00210aRCRD?orige $\mathrm{m}=$ tema\&codTema=4>. Acesso em: 12 abr. 2018.

[15] VILAÇA, Márcio Luiz Corrêa. Pesquisa e ensino: considerações e reflexões. Disponível em:
<http://revista.uniabeu.edu.br/index.php/RE/article/view/26/pdf_23 $>$. UNIABEU, 2010. Acesso em 01/05/2018 